Comparative Philosophy Volume 6, No. 1 (2015): 149-168

Open Access / ISSN 2151-6014

www.comparativephilosophy.org

CONSTRUCTIVE ENGAGEMENT DIALOGUE (1.2)

\title{
ROOTED AND ROOTLESS PLURALIST APPROACHES TO TRUTH: TWO DISTINCT INTERPRETATIONS OF WANG CHONG'S ACCOUNT
}

\author{
BO MOU
}

In this article, I suggest a distinct "pluralist" interpretation of Wang Chong's account while engaging McLeod's "pluralist" interpretation (McLeod 2011); my interpretation is essentially a substantial extension of my previously suggested general account of truth (Mou 2009) in view of relevant resources in classical Chinese philosophy as well as Wang Chong's texts. In the following discussion, my strategy is this. First, I will positively suggest one interpretation of Wang's account and explain how this interpretation is related to a general approach to the philosophical issue of truth, substantive perspectivism. Second, in view of the previous explanation, I will discuss my agreements and disagreements with McLeod, thus giving an engaging analysis of the two interpretations as two distinct pluralist approaches that I render respectively "rooted" and "rootless". Third, I will give a brief examination of explanatory forces of the two interpretations in several connections.

1.

It is a textual fact (as highlighted in McLeod 2011) that, in the classical text LunHeng, Wang Chong (王充 27-97? CE) in the Han dynasty comprehensively resorted to the general notion of shi (實 whose literal sense or basic by-default meaning is "actuality" or "reality") and treated capturing shi (實) as one general thing to unify what underlines the adequacy of any accounts, both moral ones, where shi and its contrary $x u$ (虛) (emptiness, the untrue or falsity) are pointed to respectively by the terms shi (是 right) and fei (非 wrong), and non-moral ones concerning the inclusive

MOU, BO: Professor, Department of Philosophy, San Jose State University, USA. Email: bo.mou@sjsu.edu 
natural world, ${ }^{1}$ where shi and its contrary are pointed to respectively by the terms ran (然 what is the case) and fou (否 what is not the case). What is at issue is this: What underlies such a unifying account? How is it possible to unify the two types of actuality into one general "shi" (實) category for the sake of the truth pursuit? How is it related to people's pre-theoretic understanding of truth? It is a controversial issue of how to identify and characterize such a unifying thing. In my view, (1) for Wang Chong, what fundamentally unifies the two types of actuality at the base or root level concerning truth nature consists essentially in his "normative" elaboration of people's pre-theoretic understanding of truth, i.e., capturing the (due) way things are, to be explained below; (2) at the secondary or derivative level concerning truth criterion, Wang thus uses shi-pursuing as one unifying criterion for the adequacy of both moral and non-moral ones; (3) Wang's reflective elaboration of the normative element of people's pre-theoretic understanding of truth goes essentially along with, and develops, the line of a shared reflective point among those pre-Han classical Chinese philosophers like Gongsun Long (公孫龍), Confucius (孔子) and Xun Zi (荀 子) concerning one crucial "normative" parameter or contributing element to the genuine identity of the way things are (actuality), i.e., the due way things are (their due limits and due places in the world); this crucial "normative" element constitutes one intrinsic coacervating force that fundamentally unifies two types of actuality (non-moral and moral ones) into one and two types of truth pursuit into one. In the remaining part of this section, I positively explain and argue for this interpretation of Wang's approach; in so doing, I also give an argument basis on which I will discuss McLeod's interpretation in the next section.

The issue of the relationship between language and reality has been one of the fundamental concerns in the history of classical Chinese philosophy via the issue of the relationship between name (ming) and actuality (shi). The philosophical issue of truth is intrinsically related to the issue of ming and shi in classical Chinese philosophy. It is both illuminating and engaging to understand Wang Chong's conception of $s h i$ together with its cognate notion of shi-capturing and carry out its philosophical interpretation in this broad reflective context. It is arguably correct to say that, in both ancient and contemporary times, and in various cultural traditions, people have their widely shared pre-theoretic understanding of truth, i.e., (the nature of) truth (of a truth bearer) consists in (the truth bearer's) capturing the way things are, no matter how such a pre-theoretic understanding of truth is linguistically expressed in distinct ways in different cultural-linguistic communities. People's pre-theoretic understanding of truth can be expressed (as an axiom-like thesis of truth) in the following plain way:

\footnotetext{
${ }^{1}$ It is noted that the inclusive natural world includes the natural basis of moral traits (likes moral virtues); to this extent, the non-moral and the moral are not absolutely separated and exclusive from each other, a point widely shared by many classical Chinese philosophers including those in classical Confucianism and classical Daoism. The distinction between the moral and the non-moral is thus talked about here in a limited sense.
} 
(AT) A true statement (or sentence, or belief, or...) captures the way things are,

whose more or less reflective formulation can be presented in terms of the following axiomatic thesis of the nature of truth (thus "ATNT" for short):

(ATNT) The nature of truth (of the truth bearer) consists in (the truth bearer's) capturing the (due) way things are. ${ }^{2}$

Such a pre-theoretic understanding of truth is naturally associated (more or less) with a sort of "normative" understanding of the way things are: things go their own ways or in a due course instead of in chaos; such a pre-theoretic understanding of truth is also naturally but derivatively associated with a sort of minimal "normative" expectation: what is expected is to pursue or seek capturing such ways things are. In both Chinese and other cultural traditions, people's pre-theoretic understanding of truth, together with its foregoing naturally associated "normative" understanding and expectation, has played a substantial or even tremendous explanatory and regulative role in their folk and quasi-reflective lives in dealing with the surrounding world; it is so tremendous that many reflective thinkers in various philosophical traditions who explore the fundamental relationship between language, thought and reality have endeavored to give their reflective elaborations of such a pre-theoretic understanding of truth, instead of ignoring or eschewing it, though with their distinct focuses and emphases through their distinct perspectives.

To my knowledge, perhaps Gongsun Long (320-250 BCE) is the first classical Chinese thinker who gave his reflective elaboration of the foregoing normative elements of people's pre-theoretic understanding of truth and its naturally associated relevant understanding and expectation in a general reflective way through his conception of shi (實)/actuality, although the classical Daoist thinkers Lao Zi and Zhuang Zi, Gongsun Long's contemporaries during the Warring States Period, also captured such a sentiment of people's pre-theoretic understanding of truth in their own way through the Daoist distinct conception of dao and dao pursuit in the classical texts Dao-De-Jing and Zhuang-Zi. ${ }^{3}$ Indeed, one crucial element of people's pre-theoretic understanding of truth is "the way things are", which is open to various ontological or metaphysical explanations in two major relevant senses. ${ }^{4}$ First, the phrase does not commit itself to any ad hoc ontological account of what counts as

\footnotetext{
${ }^{2}$ Cf., Mou 2009, sections 2.1 and 6.1 for more analysis of (AT) and (ATNT). The version of (ATNT) as given here has a modification "(due) way".

${ }^{3}$ For my detailed discussion of the classical Daoism on truth, see Mou 2006b and Mou 2009, ch. 5.

${ }^{4}$ Actually there is another interesting sense in which it is open to various ontological explanation: the phrase "the way things are" can mean either one piece of fact to which what, say, a sentential truth bearer literally says corresponds or a group of correlated things that what, say, a sentential truth bearer literally tells and what it implicitly or indirectly tells capture in some correlated way. I do not discuss this here as it is not directly relevant to the current issue under examination in this article.
} 
reality, whether it is a reality presently there or in the past (or even in the future), ${ }^{5}$ or whether it is physical reality or social reality or some other types of reality; in this sense, the phrase is ontological neutral in this connection. Second, it can cover both purely descriptive and somehow "normative" way things are; as explained above, people's pre-theoretic understanding implies this content when people state that things go on their own way (without excluding the possibility that things might go astray or off their own due course and thus "capturing the way things are" would include capturing the "due" way things are); to this extent, "the way things are" is both pre-theoretically compatible with, and quasi-reflectively inclusive of, both purely descriptive ways things are and "normative" due ways things are. If this "normative" point of people's pre-theoretic understanding of truth is only implicitly or compatibly delivered in a variety of folk expressions of such an understanding, Gongsun Long explicitly captured and reflectively elaborated this important "normative" element or implication of people's pre-theoretic understanding of truth through his conception of shi/actuality and shi-capturing in his account of "name rectification", which I view as one significant contribution that Gongsun Long has made to the reflective tradition of classical Chinese philosophy on the jointlyconcerned philosophical issue of truth and the contemporary theoretic exploration of the issue.

In this essay "Ming-Shi-Lun" (On Name and Actuality), Gongsun Long presents one profound vision concerning the genuine identity of actuality ${ }^{6}$ :

\begin{abstract}
天地與其所產焉, 物也。物以物其所物而不過焉, 實也。實以實其所實而不曠焉, 位也。 出其所位, 非位。位其所位焉, 正也。以其所正, 正其所不正, 疑其所正。其正者, 正其 所實也。正其所實者, 正其名也。其名正, 則唯乎其彼此焉。

"The heaven, earth and what they produce are things. When a thing goes its own way without transgressing its limit, it achieves its actuality (shi); when its actuality goes its own way without being out of its track, it achieves its due place (wei). If a thing goes beyond its due place, it is in wrong place; if a thing is in its due place, it is in right place. One is expected to rectify a thing in wrong place into right place; [one is not expected] to challenge a thing in due place [by virtue of it being in wrong place]. ${ }^{7}$ The rectification of a thing is the rectification of its actuality; the rectification of its actuality is implemented through the rectification of its name. Once its name is rectified, the standards for 'that' and 'this' will be formed up and stabilized" (my translation).
\end{abstract}

\footnotetext{
${ }^{5}$ It is noted that, though in English the term "are" in the phrase "the way things are" can be understood as the present tense of "be" (a local grammatical feature of many phonetic languages like English to which presentism or more generally speaking A-theories in the philosophy of time, is intended to be sensitive), it can be also treated as a neutral and unrestricted "existential" quantifier from an atemporal perspective (as taken by eternalism or more generally speaking B-theories in the philosophy of time), whose meaning is captured in the "absolute" unrestricted existential quantifier in the first-order logic; and the latter understanding more fits the case of Chinese language which does not have its explicit counterpart expressions for tense.

${ }^{6}$ For my previous discussion of this, see Mou 2006a.

${ }^{7}$ It has been considered that there was something missing with “疑其所正” in the original text. Here I translate it in terms of the meaning paraphrase in view of the context. Cf., Wing-tsit Chan translation of it into "[What is correct is not used to] doubt what is correct." (Chan 1963, 243)
} 
Gongsun Long here emphasizes that a thing needs to go its own way without transgressing its limit to achieve its actuality; he further stresses that, once a thing achieves its actuality, there remains an issue of how to keep its actuality in due place; he explicitly points out that the so-called name rectification lies in rectifying the actuality of a thing in its due place through rectifying the due content of its name which identifies such due place and thus gives due identity condition for the thing and its actuality. Gongsun Long here distinguishes two types of actuality: the "due-place" actuality that goes without transgressing its due place or limit, and the "undue-place" actuality that goes beyond its due place and needs to be rectified. From the vantage point of philosophical interpretation, Gongsun Long's insight of the due-place of actuality provides one profound unifying basis for the (semantic) truth concern in the Confucian account of name rectification, ${ }^{8}$ which eventually (via Xun $\mathrm{Zi}$ and Wang Chong's approaches) strives to unify the truth pursuit in the two distinct types of actuality (i.e., the actuality as the moral world and the actuality as the inclusive natural world). Gongsun Long's point here is significant in two connections: first, as indicated before, he is the first thinker in classical Chinese philosophy who explicitly suggested the conception of the due-place actuality when elaborating the normative element in people's pre-theoretic understanding of truth; second, clearly, his conception of the due-place actuality is not limited to the area of moral actuality alone but was suggested in a general way covering both non-moral and moral actuality: so capturing the way things are, to Gongsun Long, primarily means capturing the due way thing are: actuality is not limited to what appears to be there or the "status-quo" happenings but also their due places. One important implication of Gongsun Long's conception of due-place actuality is this: it provides the rationale and the metaphysical foundation for how it is possible for shi/actuality to include both nonmoral actuality and moral actuality at the base or root level. Though Gongsun Long himself did not explicitly address this significant implication of the conception of due-place actuality, it is Xun $\mathrm{Zi}$ who first explicitly addressed this idea when further elaborating and expanding relevant points of Confucius' account of name rectification, and it is Wang Chong who further developed the idea in a more explicit and comprehensive way, to be explained below.

\footnotetext{
${ }^{8}$ It is noted that, for the purpose of philosophical interpretation, I first discuss Gongsun Long's relevant thought and then Confucius' relevant thought, although the former historically appeared after the latter.

${ }^{9}$ Gongsun Long's significant influence on the issue of truth is actually dual in two lines. One line is his raising the issue of due place of actuality in his essay "Ming-Shi-Lun" (名實論 On Name and Actuality) as explained above; another line is primarily presented in this essay “Bai-Ma-Lun" (白馬論 On the White Horse) showing his semantic sensitivity to due aspects of involved objects under examination when making judgments and thus any subsequent inferences; such semantic sensibility was fundamentally shared by the later Mohists when they looked at the deep semantic-syntactic structure of the mou (侔)-style "linguistic-parallel" deductive reasoning and the adequacy condition of how to adequately apply it. For the sake of space and with consideration of the main purpose of this writing, I will not discuss the second line and the later Mohist case here, which have been examined respectively in Mou 2007 and Mou 2013.
} 
It is known that the major concern of Confucius (551-479 $\mathrm{BCE}$ ) is with moral and social issues. His doctrine of name rectification serves his major concern. The passages in the Analects that are directly related to the issue of name rectification are three: 13.3, 12.11, and 12.17. Confucius' doctrine of name rectification might as well be another way of presenting his teachings on moral cultivation and adequate governing: the teaching delivered in 12.17 is to rectify yourself to fit what those terms that signify your ranks, duties, functions and moral attributes mean (12:17), which amounts to sageliness within, while the teaching delivered in 12.11 is to participate in rectifying others to fit what those terms that signify their ranks, duties, functions, and moral attributes mean (12:11), which amounts to kingliness without. However, what really interests us here is some (explicitly or implicitly) suggested general point concerning the relation between language and reality. Let me focus on an apparent puzzle in Confucius' account that is relevant to the discussion here: there appears to be a tension between the suggested two kinds of rectification approaches. On the one hand, the trademark title of this doctrine is "name rectification", and, as highlighted in 13.3, Confucius emphasizes the significance of name rectification. On the other hand, 12.17 and 12.11 indicate that what is rectified is actually the persons who bear the (social-title) name. Which one is the primary goal while which serves as means? What is the due relation between the two kinds of rectification? Why didn't Confucius directly emphasize rectifying the moral agent? The reason seems to be this: to rectify the person (self and others) for the sake of self cultivation and of social reform, there needs a standard or norm that itself needs language as means or even as medium for the sake of its being carried out, communicated and passed on. Actually this is a two-level rectification process with the goal of rectifying the agent into a certain prescriptively specified person. The first step is to take a semantic accent strategy: instead of directly talking about how to rectify the agent, it is to first rectify her (social-title) name under examination through assigning it a certain due prescriptive content which specifies the standard or norm to be met by any eligible referents of the name and thus gives the primary identity condition of such referents. The second step is to rectify the agent based on the primary identity condition of the expected referents of the name that has been established in the preceding semantic accent strategy.

An interesting point concerning the relation between name and actuality, which is implicitly suggested by Confucius's account of name rectification is this. The due identity condition of actuality of a thing (say, a ruler) is not simply its status-quo happening or current appearance (say, the ruler-title bearing person); rather, it consists in realization of its due place without transgressing its due scope (say, the person who really possesses the moral character that is expected for the ruler); name rectification will play its important or even indispensable role through the name's carrying out and delivering the norm which specifies such a due place of the thing that is normatively denoted by the name (say, through rectifying the name "ruler"). 
At this point, one philosophically interesting question is whether this "due-place" status of moral and social identities can be extended to the non-moral world, as suggested in Gongsun Long's vision concerning the "due-place" of actuality in his conception of shi. Can the name rectification be thus extended to cover two distinct types of actuality, i.e., the actuality as the moral world and the actuality as the inclusive natural world? Though Confucius himself did not handle this issue, it is Xun $\mathrm{Zi} \mathrm{(298-238} \mathrm{BCE)} \mathrm{in} \mathrm{the} \mathrm{Confucian} \mathrm{tradition} \mathrm{who} \mathrm{(to} \mathrm{my} \mathrm{knowledge)} \mathrm{first} \mathrm{explicitly}$ addressed the issue in the Confucian tradition during the pre-Han period:

\section{...制名以指實, 上以明貴賤, 下以辨同異。}

“...create names to designate actual things for the sake of distinguishing the [morally] worthy from the [morally] unworthy at the upper level [concerning actuality as the moral world] and of distinguishing the same from the different at the base level [concerning actuality as the inclusive natural world]"] ${ }^{10}$

Xun $\mathrm{Zi}$ here talked about one general semantic relationship between names and actual things that can be further classified into two basic categories concerning distinct types of actuality, instead of three different things: the actuality as the inclusive natural world at the base level (including the natural basis of moral traits) and the actuality as the moral world at the upper level. What this is concerned with is essentially a semantic truth concern or truth pursuit, i.e., to capture the way things are: at the base level, generally speaking, the goal of creating names to designate actual things is to capture and distinguish between the same and different aspects of things, while, at the upper level where people reside in the moral and social world, the goal of creating names to designate actual things is to capture and distinguish between the (morally) worthy and the (morally) unworthy. As one prominent figure in the classical Confucianism with its primary jun-zi-moral-cultivation mission in view, Xun Zi focused on the truth pursuit at the upper level in the sense as specified above, though he explicitly addressed the issue in a general way.

If Xun $\mathrm{Zi}$ only briefly addressed the issue of whether the name rectification can be extended to cover two distinct types of actuality, it is Wang Chong during the Han dynasty who more or less systematically addressed the issue. Throughout the LunHeng (say, in those chapters like Qi-Guai, Shu-Xu, Tan-Tian, Wen-Kong, Zi-Ran, ShiZhi, Zhi-Shi, Zheng-Shuo, Dui-Zuo), as indicated before, Wang Chong comprehensively resorted to the general notion of shi (實 actuality or reality) and treated capturing $s h i$ (實) as one general thing to unify what underlines the adequacy of any account, both moral ones, where shi and its contrary $x u$ (虛) (emptiness, the untrue or falsity $)^{11}$ are pointed to respectively by the terms shi (是 right) and fei (非 wrong), and

\footnotetext{
${ }^{10}$ Xun-Zi, chapter Zheng-Ming. [My translation.]

${ }^{11}$ One might question whether $x u$ (虛) is the negation of shi (實) (thus they are contradictory) or they are merely contrary, given that the former is stronger than the latter in the sense that in a pair of contradictory sentences, one is true and the other is false, while in a pair of contrary sentences they could not both be true but could both be false. Although the text does not explicitly tell whether Wang
} 
non-moral ones concerning the inclusive natural world, where shi and its contrary are pointed to respectively by the terms ran (然 what is the case) and fou (否 what is not the case). For instance, ${ }^{12}$ in chapter Dui-Zuo, Wang Chong said:

是故《論衡》之造也, 起眾書並失實, 虛安之言勝真美也。…況論衡細說微論, 解釋世俗 之疑, 辯照是非之理, 使後進曉見然否之分。The reason why the Lung-Heng was written is this: many books fail to capture shi [truth]; the false and absurd speeches become prevalent over true and decent ones.... Through elaboration and detailed examination, the Lun-Heng sets to explain the doubts of common people, bring to light the principles of what are right and wrong through debate, and thus help those coming later clearly distinguish between what is the case and what is not the case. ${ }^{13}$

As addressed at the outset, the issue is this: What underlies such a unifying account? How is it possible to unify the two types of actuality into one general "shi" category for the sake of (semantic) truth pursuit? How is it related to people's pre-theoretic understanding of (semantic) truth? In the foregoing discussion, I positively present my interpretation of Wang's pluralist approach in the context of one prominent reflective linkage in the Pre-Han and Han classical Chinese philosophy from Gongsun Long and Confucius to Xun Zi and Wang Chong and from the point of view of philosophical interpretation, which consists of two points. First, what fundamentally unifies the two types of actuality at the base/root level concerning the nature of truth consists essentially in Wang's "normative" elaboration of people's pre-theoretic understanding of truth, i.e., capturing the (due) way things are. Second, Wang's reflective elaboration of the normative element of people's pre-theoretic understanding of truth goes essentially along with, and developed in a comprehensive way, the line of a (widely) shared reflective point made (explicitly or implicitly, generally or specifically) by various pre-Han classical Chinese philosophers such as Gongun Long, Confucius, and Xun Zi concerning one crucial "normative" parameter or contributing element to the genuine identity of the way things are (actuality), i.e., the due way things are (their due limits and due places in the world); this crucial "normative" element constitutes one intrinsic coacervating force in shi (實) that fundamentally unifies two types of actuality into one generic collection of a variety of (due) ways things are and two types of truth pursuit into one generic truth-pursuit of capturing (due) ways things are. Given that people's pre-theoretic understanding of truth is one due basis or one unifying foundation for further reflective "plural" elaborations of the nature of truth and its derivative explanatory roles from distinct

Chong treated the relationship between shi and $x u$ as contradictory or contrary, the weaker "contrary" relationship is assumed here.

${ }^{12}$ With consideration that it is agreed that Wang treated shi as univocal, and to save space, I will not make a wide range of citations from the Lun-Heng here to show the textual evidence for this. The interesting reader can examine such chapters in the Lun-Heng as Qi-Guai (奇怪), Shu-Xu (書虛), Tan-Tian (談天), Zi-Ran (自然), Shi-Zhi (實知), Zhi-Shi (知實), Zheng-Shuo (正說) besides the chapters Wen-Kong (問孔) and Dui-Zuo (對作).

${ }^{13}$ Lun-Heng, Chapter Dui-Zuo. (《论衡校注》, 569 and 571; my translation) 
perspectives, in this sense and to this extent, the foregoing pluralist interpretation of Wang's approach might as well be called a "single-foundational" or "singly-rooted" pluralist account (or simply "rooted" pluralism, given that there is only one trunk root with its many growing branches if this metaphorical term is used), in contrast to some other types of pluralist approaches or interpretations, especially "rootless" ones that are based on some second or higher order properties or functions but not rooted in the first-order truth nature per se as captured by people's pre-theoretic "(due)-waythings-are" capturing understanding of truth. I will further elaborate the basic points of the foregoing interpretation of Wang's approach when engaging McLeod's interpretation in the next section.

My interpretation presented here is essentially a substantial extension of my previously suggested general account of truth (i.e., what is labeled "substantive perspectivism") in Mou 2009 in view of relevant resources in classical Chinese philosophy as well as Wang Chong's texts. Substantive perspectivism ("SP" for short) consists of two parts: (1) a theory of truth, which I call "substantive-perspective theory" ("SPT" for sort), and (2) my surrounding remarks on behalf of the adequacy of the theory. ${ }^{14}$ My pluralist interpretation of Wang's approach can be viewed as one adding part of SPT in this sense: its normative elaboration of shi as one unifying force of non-moral and moral actuality in primarily treating truth nature and thus derivatively treating truth criterion and truth explanatory role/function constitutes one perspective elaboration instance of the basic schema of truth-nature-elaboration perspectives ("STNEP" for short) in SPT which has SPT have its open-ended character:

(STNEP) With (ATNT) as the primary elaboration-guiding axiomatic basis, for the sake of the purpose $P$, the understanding of truth nature can be elaborated in $E$,

where $P$ is replaced by a certain purpose and $E$ is replaced by a certain statement or formulation that gives the elaboration of (ATNT) for the sake of $P$. If my interpretation of Wang's account is correct, it would be not only an evidential illustration of the validity of SPT but also substantially and constructively enrich the ideology of SP in the foregoing sense.

2.

In this section, in view of my suggested interpretation, I explain my agreements and disagreements with McLeod in his interpretation of Wang Chong's approach to truth as given in McLeod 2011.

As indicated above, in the Lun-Heng, Wang Chong comprehensively resorted to the general notion of $s h i$ (實 actuality or reality) and treated capturing shi as one unifying criterion for the adequacy of any accounts, both moral ones, where shi and

${ }^{14}$ Cf., Mou 2009, chapter 6. 
its contrary $x u$ (虛) (falsity or emptiness) are pointed to respectively by the evaluative terms shi (是 right) and fei (非 wrong), and non-moral ones, where shi and its negation are pointed to respectively by the evaluative terms ran (然 what is the case) and fou (否 what is not the case). It is controversial how to identify and characterize such a unifying thing, i.e., how to understand the univocality of shi. Primarily based on his careful examination of two chapters, Wen-Kong and Dui-Zuo in the Lun-Heng, McLeod suggests his interpretation of the univocality of shi this way:

The univocality of shi is based on its second-order status. Shi, for Wang, is the property of having properties that we actually do and should seek when we appraise statements. There are a number of parts of his analysis of shi. First, it is a second-order property, but a second order pluralistic property. It is not "the property of having some (one) property such that [the truth-making description is met],"... but rather it is "the property of having properties such that [the truth-making description is met]." (55)

I agree with McLeod to the textual fact that Wang Chong did think of shi as univocal and to the evaluative judgment that, through philosophical interpretation, Wang Chong suggests a philosophically interesting pluralist account of truth. I am not merely sympathetic to, but strongly endorse, his emphasis on the ancient thinker's constructive contribution to the contemporary debate on the philosophical issue of truth. However, my major disagreement with the author's interpretation lies in how to understand and evaluate the key conception of shi in Wang's account: if my interpretation as given in the previous section is correct, (pursuing) shi (實 actuality) does not primarily mean the second-order property that the author identifies, but primarily means (pursing) the first-order nature of truth, i.e., capturing the (due) way things are, whose "normative" coacervating force underlies the unification of two areas of shi capturing (non-moral and moral areas) and thus two types of shi pursuit; in contrast, what is identified by the author as the second-order property is essentially one derivative explanatory role played by the first-order nature of truth; such an explanatory role of describing what we actually seek and prescribing what we should seek when we appraise statements is not directly concerned with the primary issue of what truth is (the nature of truth itself) but with the derivative issue of what explanatory-roles can be derivatively played by the already understood concept of truth. In the following, I further explain this major disagreement by examining how the author argues for his interpretation of Wang's approach.

Immediately after presenting his "second-order-property" interpretation of Wang's conception of shi/shi-pursuit in section 3.4 as cited above, in the subsequent passage McLeod provides his justification for this interpretation as follows (55-56):

Shi, for Wang, can be thought of as expressing a second-order property-the property of having a property or properties that we should and do seek when appraising statements. This makes truth rest on normativity. The normativity involved here, however, is basic, in a sense that what we should do is linked with what we do in fact do, but is not explained by the fact that we do these things. That is, the descriptive element is not meant to 
explain the normative, but be a further basic fact beside it. Here, both concepts are in the employ of the truth function, as an explanation for what makes a particular statement shi. If we consider the properties of 然 ran and 是 shi that can belong to statements in the non-moral and moral domains, respectively, we can begin to see what is meant. The properties of ran and shi are properties humans naturally seek when they appraise sentences, according to Wang. No one accepts as true a statement they believe to be 不然 bu ran or 非 fei. Rather, the reason a statement is accepted by anyone is because one believes (sometimes mistakenly) that this statement is either 然 ran, 是 shi, or has some other 實 shi-making property. It is a brute fact about humans that we do seek properties such as 是 shi and 然 ran when we appraise sentences and accept or believe statements based on whether or not we have reason to think they are ran or shi. Thus the key question to be answered when we consider whether or not something is 實 shi is whether the statement actually has the properties we naturally seek. In addition to this description of what humans actually do, however, there is an added normative element. Not only $d o$ we seek properties like 然 ran and 是 $s h i$, but we ought to seek such properties. Why ought we? That is, what explains the normativity? I believe (though it would take much more space than I have here to argue) that Wang takes this normativity as explanatorily basic.

In my view, there are several difficulties with this argument. First, the basic point of the passage is to identify some socio-epistemic feature of our truth pursuit process, in the author's terms, a sort of second-order property of having properties that we actually do and should seek when we appraise statements; such a second-order property is essentially a certain derivative explanatory role played by (the concept of) the primary first-order nature of truth [i.e., capturing the (due) way things are]; this primary first-order nature of truth is pre-theoretically delivered by people's pretheoretic understanding of truth, and its first-order "normative" point, as explained in the previous section, is reflectively elaborated via Wang's unifying conception of shi (實 actuality) and shi-capturing along with the line from Gongsun Long and Confucius to Xun $\mathrm{Zi}$ on the relationship of ming (names) and shi (actuality). The point here is not to deny the existence of such a second-order property as a certain socio-epistemic feature of our truth pursuit process; what is at issue is whether it is primary or derivative - it is based on something more basic or rootless on its own. Conceptually speaking, what is identified by the author as the second-order property is essentially one derivative explanatory role played by the already understood concept of the first-order nature of truth as presented in people's pre-theoretic understanding of truth; in other words, such an explanatory role of describing what we actually seek and prescribing what we should seek when we appraise statements is not directly concerned with the primary issue of what truth is (the nature of truth itself) but with the derivative issue of what explanatory-roles can be derivatively played by the already understood concept of truth; it is derivative in the sense that such a explanatory role needs to be understood and explained on the basis of the primary issue of what truth is. If my interpretation as suggested in the previous section is right, Wang's conception of shi and shi-capturing is essentially concerned with both issues addressing distinct "normative" elements in people's pre-theoretic understanding of 
truth and its naturally associated understanding and expectation: at the primary base level, via maintaining (instead of dramatically altering) the basic folk meaning of shi (實) as actuality and along with the aforementioned reflective line from Gongsun Long and Confucius to Xun $\mathrm{Zi}$, Wang Cong addresses the issue of what truth is and resorts to the inclusive conception of shi (with its unifying "due-place" implication) to characterize the (first-order) nature of truth involved in both moral and non-moral accounts, while at the secondary derivative level, he addresses the normative explanatory role played by the already understood concept of truth or shi-capturing and identifies some socio-epistemic normative feature of our truth pursuit process.

Second, McLeod's interpretation of Wang's conception of shi as a kind of second-order property dramatically deviates from the pre-Han folk understanding of the term shi as the expression of the concept of actuality which is closely related to the folk expression of people's pre-theoretic understanding of truth in ancient China. Indeed, there were a range of shi-related folk expressions in the classical Chinese before or around Wang's times (the pre-Han and Han periods) that were used to deliver people's pre-theoretic the-(due)-way-things-are-capturing understanding of truth, such as “ze-shi” (責實) or “ze-qi-shi” (責其實) meaning “to pursue the way things are", 15 “shi-shi-qiu-shi” (實事求是) meaning “to pursue what are based upon what really are". ${ }^{16}$ One can identify two key Chinese terms, or their cognates, that

\footnotetext{
${ }^{15}$ See Chapter “Ding-Fa” (定法) of the Han-Fei-Zi (韓非子) [the Chinese original text]. It is interesting to note this: two appearances of the term 'shi' (實) in the phrase 'ze-shi' (or 'ze-qi-shi') in two distinct contexts (i.e., that of 'she-gao-xiang-zuo-er-ze-qi-shi' 設告相坐而責其實 and that of 'xun-ming-er-ze$s h i$ ' 循名而責實) in this chapter suggest that what the term expresses (i.e., the way things are) can be either the way things are in the actual world or the way things are in some reality conceptually introduced/specified or socially created by human beings.

${ }^{16}$ This is a four-character predicative proverb in classical Chinese which, like many other fourcharacter predicative proverbs in classical Chinese, is still widely circulated even in the modern Chinese linguistic community. For one of its ancient uses, see '修學好古實事求是' in Chapter “HeJian-Xian-Wang-Zhuan" (河間獻王傳) of the Han-Shu (漢書). Even in contemporary China, it is still a significant slogan which is illustrated by this: one national journal in the mainland China is currently entitled 'Qiu-Shi' (求是), meaning pursuing truth. Note that, the character 'shi' in this context, strictly speaking, is used as a demonstrative pronoun which points to the source of the truth, i.e., the real situation or the way things are, which is what 'shi-shi' (實事) denotes. The translation of 'shi' (是), 'what this is', in my paraphrase of the predicative proverb in the main text ('to pursue/capture what this is based on the real situation [or on the way things are]', or simply, 'to pursue/capture the way things are') is actually an extended meaning in the context of the demonstrative use of the character 'shi'. As I see it, this predicative proverb is a good example to show how the two uses, or two meanings, of 'shi' mentioned in the previous note are connected; more significantly, the literal sense of 'qiu-shi' (to pursuit what are / the way things are) gives the core of our pre-theoretic "way-things-are capturing" understanding of truth in a non-semantic-ascent, explanatory-reduction way.

It is noted that $s h i-w u$ 實物 and $s h i-s h i$ 實事 are intrinsically related, instead of separated: when one uses name to designate one thing or object as a whole (shi-wu) via a certain identity criterion, one simultaneously refers to a certain aspect of the object which is focused on via the identity criterion and thus says something of the object or what is true of the object (shi-shi). This semantic fact indicates the superficiality of the distinction between the sentential and non-sentential. This semantic fact also shows that, as the two aspects of shi are intrinsically related, even if it was a historical fact that the preQin usage of shi tended to focus on its "shi-wu" aspect while the post-Qin usage tended to focus on its
} 
essentially appear in all those folk expressions: one is the term “shi” (是) or “shi” (实) which means what are or what really are (or the way things are), and the other the term 'qiu' (求) or ' $z e$ ' (責) which means pursuing/seeking/capturing or fitting. Because there is no textual evidence in the Lun-Heng text showing that Wang Chong used the term "shi" (實) in some dramatically different meaning from its by-default literal sense (he neither explicitly indicated nor implicitly suggested any substantial meaning alternation), it is reasonable to assume that Wang used the term "shi" and various "shi"-related phrases in the Lun-Heng primarily in its basic "first-order" sense, meaning actuality (thus "qiu-shi" meaning actuality-capturing), instead of dramatically altering its basic folk meaning to primarily mean a "second-order" property.

Third, McLeod's interpretation of Wang's conception of shi has Wang's approach significantly deviated from one significant reflective line from Gongsun Long and Confucius to Xun Zi which Wang Chong's account is considered to inherit and develop: as explained in the previous section, via Gongsun Long's conception of the due-place actuality, this reflective line essentially gives a reflective elaboration of the "first-order" normative element of the folk notion of shi and of people's pre-theoretic understanding of truth (capturing shi) in ancient China. As I have explained this issue in the previous section, I address this difficulty only briefly here. Fourth, in indicating that "shi, for Wang, can be thought of as expressing a second-order property" (my emphasis), McLeod is correct in acknowledging that Wang's textual remarks in the Lun-Heng are open to, or compatible with, distinct interpretations. After he explains what the normative is in truth pursuit ("we ought to seek such properties [like 然 ran and 是 shi]"), McLeod gives his crucial statement in his argument as follows: "Thus the key question to be answered when we consider whether or not something is 實 shi is whether the statement actually has the properties we naturally seek. In addition to this description of what humans actually do, however, there is an added normative element. Not only do we seek properties like 然 ran and 是 shi, but we ought to seek such properties. Why ought we? That is, what explains the normativity? I believe (though it would take much more space than I have here to argue) that Wang takes this normativity as explanatorily basic." The reader at this point would wonder: what is the author's justification for his conclusion that "Wang takes this normativity as explanatorily basic"? There is a substantial gap between the author's acknowledgement that Wang's text is open to distinct interpretations and his belief here that Wang takes the alleged second-order

\footnotetext{
"shi-shi" aspect (cf., Makeham 1994; in view of Xu Gan's usage of shi in this connection, Makeham translates it into "actuality" or "a state of development peculiar to an entity or state of affairs by virtue of which that entity or state of affairs is what it is" [ibid., 7]), it would not constitute a substantive denial of the interpretative thesis that we might as well label the truth-concern orientation of classical Chinese philosophy in terms of 'shi-shi-qiu-shi' (實事求是: 'to pursue what are based upon what really are'). This basic semantic fact was actually addressed both by Gongsun Long and the later Mohist. For a theoretic but schematic discussion of this "double-reference" semantic fact and of how Gongsun Long addressed it in his "White-Horse-Not-Horse" argument, see Mou 2007.
} 
normativity as explanatorily basic, especially in view of the foregoing three difficulties, each of which suggests some other substantial dimension of Wang's account; McLeod has yet to explain why he arrives at the latter from the former but simply stating that "it would take much more space than I have here to argue". This renders McLeod's argument for his interpretation weak at this key point.

Among the foregoing four difficulties, the first one is a theoretic one that I render more serious than the others - actually a difficulty to (or a problem with) any "second (or higher) order property"-principled pluralist approaches including those in the contemporary debate on the issue $;^{17}$ the point of raising this difficulty consists of two general points: (1) what is missed is the real basis or root and due foundation whose central point is captured by people's pre-theoretic understanding of truth concerning the first-order nature of truth and whose various aspects and layers have been, and can be further elaborated from distinct already-presented or coming perspectives in treating the philosophical issue of truth; (2) some derivative second (or higher) order property is arguably mis-located at the primary basis, as it is a part of a variety of (normative or prescriptively identified) explanatory roles or functions that are essentially and eventually played by the already understood concept of truth as captured by people's pre-theoretic understanding of truth. However, as what the author intends to give is a philosophical interpretation instead of a purely historical description, the author can ignore the foregoing second and third difficulties or render them not fatal to this extent: it does not matter whether this interpretation is in accordance with the pre-Han folk usage and meaning of shi or with the aforementioned line from Gongsun Long and Confucius to Xun $\mathrm{Zi}$; the author can legitimately emphasize that the primary goal of what is done in his interpretation is to elaborate some implied philosophical interesting content of Wang Chong's classical text and think about its contribution to the contemporary debate. To the similar extent, the author can even legitimately (I think) dismiss the foregoing fourth difficulty: the goal is not to detect and tell what exactly ran in Wang Chong's head but give an interpretative elaboration of something philosophically interesting that is implied in the classical text Lun-Heng, whether or not Wang Chong as a historical figure was then really aware of it. ${ }^{18}$ McLeod seems to realize others' possible criticism in this connection when he gives a note on the previous page as follows:

Although Wang perhaps did not explicitly have a pluralist view like the one I sketch below, I think this theory is the best way to make sense of what Wang says in the LunHeng concerning shi, as it makes his position strongest, even though what he says is also compatible with a number of other interpretations, including the possibility that the differences between evaluative terms in different contexts were merely stylistic. Although I import the conceptual apparatus of contemporary analytic philosophy to reconstruct Wang's view of truth, I realize that this distorts Wang's view to the extent that Wang did not work with such a conceptual apparatus. Much of what follows below is

\footnotetext{
${ }^{17}$ For example, Lynch 2001.

${ }^{18}$ For a detailed discussion of mine on some methodological issues involved in philosophical interpretation and historical description of ancient thinkers and their texts, see Mou 2002.
} 
my attempt to reconstruct Wang's basic view of truth and extend it using the tools available to contemporary philosophy. Thus, much of what follows is not explicitly held by Wang, but rather is a natural way of developing his pluralist view of truth. As such, it can be seen as continuous with Wang's theory of truth, even if it is less useful for understanding the way early Chinese thinkers theorized about truth (although the general pluralism I attribute to Wang above can, I think, be useful for this latter project as well) (53, footnote 33$)$.

Fair enough. However, for one thing, insofar as McLeod still hopes that his interpretation would "[be] useful for understanding the way early Chinese thinkers theorized about truth", failing to take the foregoing second, third and fourth difficulties seriously would substantially hurt the explanatory force of the author's interpretation in some relevant connections. For another thing, McLeod seems too quick to view his interpretation as "the best way to make sense of what Wang says in the Lun-Heng concerning shi, as it makes his position strongest" (my emphasis in italics) as he has yet to consider and engage other promising interpretations and thus justify this "best way" judgment. In the next section, I will evaluate McLeod's "best way" judgment on his interpretation by looking at the explanatory forces of the two interpretations under examination.

3.

In this section, I briefly evaluate explanatory forces of the two pluralist interpretations of Wang Chong's approach under examination in this article, i.e., McLeod's secondorder-property-principled interpretation ("SOP interpretation" for short) and my substantive-perspective-elaboration interpretation ("SPE interpretation" for short). In the following, I address four connections in which their respective explanatory forces are discussed. ${ }^{19}$

First, as far as their relationship with people's pre-theoretic understanding of truth is concerned, the SPE interpretation gives an account of how Wang's approach is essentially based on, and constructively elaborates, people's pre-theoretic understanding of truth concerning truth nature though his conception of shi and shicapturing; in contrast, the SOP interpretation (or any other second or higher order property account like Lynch's) is not based on people's pre-theoretic understanding of truth for the sake of characterizing truth nature. Given that people's pre-theoretic understanding of truth is one due basis or root for further reflective and theoretic explanation of the nature of truth and its derivative explanatory roles, ${ }^{20}$ the SPE interpretation thus provides a "rooted" pluralist approach while the SOP interpretation

\footnotetext{
${ }^{19}$ For a comparative analysis of the similarity and distinctions between my pluralist account and some other contemporary pluralist accounts like Wright 2001 and Lynch 2001, see Mou 2009, 176-9, which also addresses the issue of their explanatory force.

${ }^{20}$ In my theoretic account (Mou 2009), as partially highlighted below from the non-revisionist methodological vantage point in this regard, I argue for a stronger case that people's pre-theoretic understanding of truth should be the single one unifying foundation for further reflective and theoretic explanation of the nature of truth and its derivative explanatory roles.
} 
is "rootless" in this connection. Indeed, given that Wang's conception of shi is essentially in accordance with people's pre-theoretic understanding of truth, and given that the SOP account is intended to be at least compatible with this pretheoretic understanding of truth (though it is not based on it), an examination of the explanatory force of the two interpretations in this connection is meaningful. It is noted that there are two basic attitudes towards people's pre-theoretic understanding of the truth nature: the non-revisionist versus revisionist ones. It seems that, to some extent, or strictly speaking, the SOP account holds a sort of revisionist attitude towards the truth nature when it is intended to take the addressed second-order property to be "explanatorily basic". The non-revisionist attitude is conceptually related to a general non-revisionist attitude in philosophy to the effect that philosophy should not be revisionary of our intuitive understanding or folk usage about the matters in question unless there are very strong theoretical or practical reasons in favor of revision; the non-revisionist attitude is supported by the following general methodological principle: if there are two conflicting alternative theoretical approaches to an issue, and if one of them is more intelligible from a point of view of our pre-theoretic understanding on the issue (or labeled "untutored intuition") than the other, then the burden of proof is on the latter to show that there is something wrong with untutored intuition; if such a proof cannot be given, our theoretic model should preserve as many of our intuitions about the issue as possible. Whether or not the above general non-revisionist attitude and its associated general methodological principle should be generally adopted in philosophical inquiries, it seems to be reasonable to take it as one basic methodological strategy in treating the philosophical concern with truth, especially the issue of the truth nature. Due to some indispensable explanatory role played by our pre-theoretic understanding of truth in people's folk and reflective lives, there seem no strong theoretical or practical reasons in favor of fundamental revision concerning the truth nature as captured by people's pretheoretic understanding of truth.

Second, as far as their respective explanatory force in helping understand the way early Chinese thinkers theorized about truth is concerned, the SPE interpretation gives an account of how Wang's approach is essentially related to and develops one significant reflective line from Gongsun Long and Confucius to Xun $\mathrm{Zi}$ : as explained in the previous section, via Gonsun Long's conception of the due-place actuality, this reflective line essentially gives its reflective elaboration of the "first-order" normative element of the folk notion of shi and of people's pre-theoretic understanding of truth in ancient China (capturing shi).

Third, as far as their respective explanatory relationship to a variety of contemporary approaches to the issue of truth is concerned, the SPE interpretation, as one perspective elaboration of people's pre-theoretic understanding of truth, is not only compatible but also complementary to many other perspective elaborations concerning distinct aspects and layers of people's pre-theoretic understanding of truth as captured in its reflective formulation (ATNT). For example, in the framework of the SPE interpretation, Wang's approach and Tarski's approach can talk with each other on the shared basis as they are rooted in the same pre-theoretic understanding of 
truth. I choose Tarksi's approach to illustrate the point here with consideration that Tarski's contemporary semi-formal approach appears to be so different from that of an ancient Chinese thinker like Wang Chong. From the point of view of the SPE interpretation in the framework of SP, Tarski's account of material adequacy condition for a truth definition is essentially a truth-definition-adequacy perspective elaboration with regard to adequacy condition of a truth definition. ${ }^{21}$ Now both Tarski's approach and Wang's approach are essentially distinct perspective elaborations of people's pre-theoretic understanding of truth; they are not merely compatible with each other but also can learn from each other and make joint contribution to a complete account of the philosophical issue of truth. For Wang's approach, Tarski's approach not merely can provide rich conceptual and explanatory resources for formally correct presentation of an account of truth including Wang's

${ }^{21}$ This Tarskian truth-definition-adequacy elaboration perspective can be explicitly formulated as follows (essentially in Tarskian resources in Tarski 1933, though Tarski did not formulate it this way; for more explanation of it, see Mou 2001/2009):

With (ATNT) as the primary elaboration-guiding axiomatic basis, for the sake of characterizing the adequacy condition of a truth definition, the understanding of the nature of non-linguistic truth can be elaborated into the following general definition, (TDA), of what it is to be a definition of truth (the non-linguistic truth):

(TDA): For any language $L$, set $\mathrm{S}_{L}$ of sentences of $L$, and any meta-language $M L$ of $L$ in the following meta language of $M L$ :

$\Delta$ is a truth-definition for $L$ in $M L$ if and only if

(1) $\quad L$ is any well-behaved language which is constructed over a non-empty vocabulary of non-logical expressions;

(2) $\quad M L$ is a language which includes the following items:

(2a) a structural-descriptive name, $\partial(\varphi)$, of every sentence $\varphi$ in $\mathrm{S}_{L}$;

(2b) there is a map $\Gamma: L \Rightarrow M L$, which assigns to each sentence $\varphi$ in $\mathrm{S}_{L}$, a translation $\Gamma$

$(\varphi)$ in $M L$;

(2c) a structural-descriptive name, $\partial(L)$ for $L$;

(2d) a biconditional sign, $\leftrightarrow$;

$M L$ contains a two-place predicate, say ' $\pi(x, \partial(L))$ ' such that

(3a) " $\pi(x, \partial(L))$ " does not occur in $L$ and is the only semantic notion to be defined;

(3b) the definition $\Delta$ is $\forall x(\pi(x, \partial(L)) \leftrightarrow \Psi(x, \partial(L)))$, where $\Psi$ is a dyadic $M L$ predicate;

(3c) a metatheory $M T$ in $M L$ contains $\Delta$ and other axioms and syntactic rules regarding $L$ that are expressed in $M L$;

(3d) $M T \longmapsto \pi(x, \partial(L)) \leftrightarrow \Gamma(\varphi)$, for each $\varphi$ in $\mathrm{S}_{L}$;

(3e) $M T \vdash \neg \Gamma(\varphi) \square \rightarrow \neg \pi(x, \partial(L))$,

where $\square \rightarrow$ is the counterfactual conditional in $M L$;

(3f) $\Delta$ has the schema (T) as its extending-pattern in this sense:

$M T \vdash \pi\left(\partial(\phi), \partial\left(L^{*}\right)\right) \leftrightarrow \Gamma(\phi)$, for each $\phi$ in $\mathrm{S}_{L^{*}}$

where $\phi$ would be any sentence which is newly added to $L, L^{*}$ would be the extended language whose set $\mathrm{S}_{L^{*}}$ of sentences is $\left\{\mathrm{S}_{L}, \phi\right\}, \partial(\phi)$ is the structuraldescriptive name of $\phi$ in the extended metalanguage $M L^{*}$ of $L^{*}$, and $\partial\left(L^{*}\right)$ is the structural-descriptive name of $L^{*}$ in $M L^{*}$, and $\Gamma(\phi)$ is the translation of $\phi$ in $M L^{*}$. 
approach when in need of its more precise formulation (say, for the sake of avoiding the semantic paradox), but can be also complementary to Wang's approach with regard to (material) adequacy of a truth definition. For Tarski's approach (and, more generally speaking, for some other approaches in contemporary philosophy), Wang's descriptive-normative-unification perspective elaboration of people's pre-theoretic understanding of truth can contribute to a certain constructive expansion of Tarski's approach and, more generally speaking, the contemporary exploration of the philosophical issue of truth.

Fourth, the SPE interpretation can include the crucial perspective dimension of the SOP interpretation, even though it is hard for the latter to include the crucial dimension of the former. As indicated before, the point of my suggested interpretation is not to reject the existence or the raison d'etre of the second-order property per se of having properties that we actually and we should seek but explain its due status and where it needs to be located. In my general account, it is to be located in the explanatory-role project concerning an understood substantive notion of truth regarding the explanatory-role dimension of the philosophical concern with truth; in this project some antecedently understood (substantive) notion of truth is systematically used for broader philosophical purpose; it serves either as an explanatory norm to regulate one goal of our philosophical inquiries (like what most of philosophers intend to pursue in their philosophical inquiries) or as an explanatory basis to explain other important things in philosophy (like what Davidson's project endeavors to do). In my view, it is essentially a variant of what is sometimes labeled "the thesis of truth centrality as a (strategic) normative goal" to the effect that:

Truth (nature) or capturing the (due) way things are, as characterized by (ATNT), is an explanatory norm to regulate and explain one central strategic goal of philosophical inquiries,

which per se is one representative perspective elaboration of the following thesis of truth centrality concerning its explanatory role:

Truth (or the concept of truth), as characterized by (ATNT), plays its indispensable, central explanatory role in philosophical inquires.

The foregoing thesis of truth centrality concerning its explanatory role is concerned with a variety of explanatory roles played by the fundamental concept of truth (the nature of truth) as reflectively captured by the axiomatic thesis of the nature of truth (i.e., the ATNT thesis) and pre-theoretically delivered by people's pre-theoretic understanding of truth. In this sense, and to this extent, the normative property of our pursuit of truth as captured by the above thesis of truth centrality as a (strategic) normative goal in our philosophical and other inquiries is a second-order property; however, as explained in the previous section, such a second-order property is a derivative properties rather than the primary property of truth (or the nature of truth). 


\section{ACKNOWLEDGEMENTS}

I am grateful to Lajos Brons, Xiaojun Ding, Dean P. Dominguez, Marshall Willman, and Hongyin Zhou for providing helpful critical feedback on a draft of this article.

\section{REFERENCES}

Chan, Wing-tsit (trans. and comp.) (1963), A Source Book in Chinese Philosophy (Princeton University Press).

Dao-De-Jing 《道德經》[the Chinese original text].

Gong-Sun-Long-Zi 《公孫龍子》[the Chinese original text].

$H a n-F e i-Z i$ 《韓非子》[the Chinese original text].

Lun-Heng 《論衡》[by Wang Chong (王充), the Chinese original text. The original text on which the relevant part of this essay is based: 《論衡校注》張宗祥校注 (上 海古籍出版社, 2013)]

Lynch, Michael (2001), "A Functionalist Theory of Truth", in M. Lynch (ed.), The Nature of Truth (MIT Press), 723-49.

Makeham, John (1994), Name and Actuality in Early Chinese Thought (SUNY Press). McLeod, Alexus (2011), "Pluralism about Truth in Early Chinese Philosophy: A Reflection on Wang Chong's Approach", Comparative Philosophy, 2.1: 38-60, $<$ www.comparativephilosophy.org/index.php/ComparativePhilosophy/article/vew $137 / 87>$

Mou, Bo (2001), "The Enumerative Character of Tarski's Definition of Truth and Its General Character in a Tarskian System," Synthese, 126: 91-122.

- (2002), "Three Orientations and Four 'Sins' in Comparative Studies," in the APA Newsletters (in the part on comparative philosophy ed. by Chenyang Li), Fall 2002, 2:2: 42-5.

- (2006a), "Chinese philosophy: language and logic," in Donald M. Borchert, (ed.), Encyclopedia of Philosophy (2nd edition) (Macmillan Reference USA), 202-215.

- (2006b), "Truth Pursuit and Dao Pursuit: From Davidson's Approach to Classical Daoist Approach in View of the Thesis of Truth as Strategic Normative Goal," in Bo Mou (ed.), Davidson's Philosophy and Chinese Philosophy (Brill), 309-349.

- (2007), "A Double-Reference Account: Gongsun Long's 'White-Horse-NotHorse' Thesis," The Journal of Chinese Philosophy, 34.4: 493-513.

- (2009), Substantive Perspectivism: An Essay on Philosophical Concern with Truth ("Syntheses Library" monograph series, vol. 344; Dordrecht: Springer).

- (2013), "Semantic-Syntactic Structure of the Mohist 'Mou'-Type Inference and an Enhanced Predicate Logic System" (unpublished), presented at the 2014 Beijing Roundtable Workshop (28 ${ }^{\text {th }}$ June 2014).

$M o-Z i$ 《墨子》[the Chinese original text]. 
Tarski, A. (1933), "The Concept of Truth in Formalized Language", in A. Tarski (1983), Logic, Semantics, Metamathematics ( $2^{\text {nd }}$ edition), translated by J. H. Woodger (Indianapolis: Hackett), 152-278.

Wright, Crispin (2001), "Minimalism, Deflationism, Pragmatism, Pluralism", in M. Lynch (ed.), The Nature of Truth (MIT Press), 751-788.

Zhuang-Zi 《莊子》[the Chinese original text]. 